\title{
Effects of Acylcarnitine-Transferase Inhibitors on Adenine Nucleotide Metabolism and Ischemic Tissue Injury in Isolated Perfused Rat Heart
}

\author{
Hisataka Shikama, Ph.D., Osamu Noshiro, B.Sc., \\ Akiko Ohta, B.Sc., and Isao Ohata, Ph.D.
}

\section{SUMmary}

The ability of irreversible acylcarnitine-transferase inhibitors, sodium 2[5-(4-chlorophenyl)-pentyl]-oxirane-2-carboxylate (POCA) and 2-tetradecyl-glycidic acid (TDGA), to reduce myocardial ischemic injury was studied in Langendorff-perfused hearts exposed to ischemia (zero $\mathrm{mmHg}$ ) followed by aerobic reperfusion $(60 \mathrm{mmHg})$. Rat hearts were pretreated with either POCA $(15 \mathrm{mg} / \mathrm{kg}$ ) or TDGA $(5 \mathrm{mg} / \mathrm{kg})$ s.c. $120 \mathrm{~min}$ before the perfusion. Treated hearts showed a decreased release of creatine kinase and lactate on reperfusion after $30 \mathrm{~min}$ ischemia. POGA-treated hearts showed significantly higher ATP concentrations than control hearts on reperfusion. POCA also improved the maximum recovery of the pressure-rate product but with a significant delay. During the ischemic period, though, POCA decreased the ATP concentration at a rate three times that of controls during the first $10 \mathrm{~min}$. No further reductions were observed for up to $30 \mathrm{~min}$ of ischemia. TDGA also showed a reduction of ATP. Thus, the observation that POGA stimulated ATP synthesis and reduced creatine kinase release on reperfusion after ischemia suggests that this agent provides some protection to the ischemic myocardium. However, during ischemia, it is likely that the depletion of ATP concentration induced by POCA resulted in delayed recovery of mechanical function on reperfusion.

\section{Additional Indexing Words:}

Acylcarnitine-transferase inhibitors Free fatty acids oxidation Myocardial energy metabolism Perfused rat heart

M

YOCARDIAL ischemia releases catecholamines which stimulate lipolysis and oxidation of free fatty acids (FFA). ${ }^{1,2)}$ This process is believed to be one of the causes for the development of ischemic injury because of an increase in oxygen consumption ${ }^{3)}$ and/or inhibition of adenine nu-

From the Department of Biochemistry, Central Research Laboratories, Yamanouchi Pharmaceutical Go., Ltd., Tokyo, Japan.

Address for reprints: Dr. Hisataka Shikama, Department of Biochemistry, Central Research Laboratories, Yamanouchi Pharamaceutical Co., Ltd., 1-1-8, Azusawa, Itabashi-ku, Tokyo 174, Japan.

Received for publication April 23, 1987.

Accepted April 11, 1988. 
cleotide translocase. ${ }^{*)}$ Even though little is known about the role of the accumulation and oxidation of FFA and acyl CoA on ischemic injury, the therapeutic significance of a reduction of FFA oxidation has already been provided using agents that act by various mechanisms. Oxfenicine (S-4hydroxyphenyl glycine), ${ }^{5}$ TDGA ${ }^{67}$ and POGA $^{7)}$ inhibit FFA oxidation at the level of acylcarnitine-transferase in mitochondorial inner membrane, resulting in the stimulation of glucose oxidation associated with the activation of pyruvate dehydrogenase. ${ }^{8)}$ The latter two agents inhibit acylcarnitine-transferase in an irreversible manner. ${ }^{6)}$

Oxfenicine reportedly improves recovery of mechanical function and reduced ischemic damage in rat heart ${ }^{9)}$ and in canine heart. ${ }^{10)}$ Furthermore, Pearce et al, using the technique of pyridine nucleotide surface fluorescence photography, showed that addition of oleate to hypoxic heart increased the size and number of anoxic areas and that subsequent addition of TDGA caused the anoxic areas to disappear. ${ }^{11)}$ However, Seitelberger et al observed that POCA exerted no beneficial effects on regional function in the underperfused canine myocardium, although FFA uptake was reduced significantly. ${ }^{12)}$

This study was conducted to determine: (a) if inhibition of endogenous FFA oxidation by irreversible acylcarnitine-transferase inhibitors (POCA and TDGA) leads to improved recovery of mechanical function and reduction of enzyme leakage in ischemic, reperfused rat hearts and (b) if a switch from preferential endogenous FFA oxidation to carbohydrate oxidation improves energy metabolism during ischemia.

\section{Materials And Methods}

Animals:

Male Sprague-Dawley rats weighing 350-400 $\mathrm{g}$ were deprived of food overnight but were allowed free access to water. They were anesthetized with pentobarbital ( $45 \mathrm{mg} / \mathrm{kg}$, i.p.). Immediately before the excision of the heart, heparin (100 IU, Novo, Denmark) was injected into the femoral vein.

Measurement of long-chain fatty acid oxidation:

The heart was homogenized in 9 vol of $0.25 \mathrm{M}$ sucrose. An aliquot of homogenate $(0.1 \mathrm{ml})$ was incubated at $37^{\circ}$ for $60 \mathrm{~min}$ in $0.9 \mathrm{ml}$ KrebsHenseleit bicarbonate (KHB) buffer ( $\mathrm{pH} 7.4$ ) containing $0.5 \mu \mathrm{Ci}\left[1-{ }^{14} \mathrm{C}\right]$ palmitate, $2 \mathrm{mM}$ ATP, $0.16 \mathrm{mM} \mathrm{CoA}, 2 \mathrm{mM}$ L-carnitine and $0.1 \%$ bovine serum albumin. After the reaction was stopped by addition of $0.2 \mathrm{ml} 2 \mathrm{M}$ $\mathrm{HClO}_{4}$, the $\mathrm{CO}_{2}$ evolved was absorbed by $0.2 \mathrm{ml}$ Scintilamine-OH (Dotite, Kumamoto). The radioactivity was determined using appropriate quench 
corrections. Protein was measured by the method of Lowry et al. ${ }^{13)}$

\section{Heart perfusion:}

The perfused heart preparation used a modified method of Langendorff, which included cannulation of the aorta and a constant perfusion pressure of $60 \mathrm{mmHg}{ }^{14)}$ The perfusion medium was made up of KHB buffer containing $11 \mathrm{mM}$ glucose, equilibrated with a gas mixture of $95 \% \mathrm{O}_{2}+5 \% \mathrm{CO}_{2}$. The perfusion medium was filtered through a $1.6 \mu \mathrm{m}$ filter. The perfusate was not recycled in a flow-through system. The temperature of the perfusate and perfused heart was maintained at $37^{\circ}$ with double-layered water jackets.

Time sequence of experiments:

POCA $(15 \mathrm{mg} / \mathrm{kg})$ or TDGA $(5 \mathrm{mg} / \mathrm{kg})$ was injected s.c. $120 \mathrm{~min}$ before the start of the perfusion. The dosage of drugs and time interval used were estimated by the activation of pyruvate dehydrogenase in rat heart (data not shown). These drugs were dissolved in ethanol and 10\% Cremophor ER solution (Nakarai Chemicals, Kyoto).

Initially, the hearts were perfused for $15 \mathrm{~min}$ (the control period) with oxygenated KHB buffer and then they were submitted to ischemia (zero $\mathrm{mmHg}$ ) up to $60 \mathrm{~min}$. After ischemia, aerobic perfusion was restored again (the reperfusion period). Samples of the coronary effluent were collected every two minutes, except for the first 5 min after the start of the reperfusion, during which the whole effluent was collected for analysis of creatine kinase and lactate. The coronary flow was monitored by timed collection of perfusate. For the determination of intracellular concentrations of ATP, ADP and AMP, hearts were quick-frozen at appropriate times with aluminum clamps pre-cooled in liquid nitrogen and then pulverized. Dry weights of the hearts were determined by drying tissue powder at $80^{\circ}$ for $36 \mathrm{~h}$.

\section{Mechanical function:}

Intraventricular pressures, pcak left ventricular pressure (LVP) and left ventricular end-diastolic pressure (LVEDP), were measured by inserting a needle through the apex of the heart into the left ventricle. Heart rate (HR) was measured with a frequency counter from the left ventricle pressure records. The product of (LVP-LVEDP) $\times$ HR was used as an index of mechanical function.

Analytical methods:

Adenine nucleotide, ATP, ADP and AMP151,16) were enzymatically determined. Concentration was expressed as $\mu \mathrm{mol} / \mathrm{g}$ dry tissue wt. Creatine kinase was measured by the method of Urdal and Stromme. ${ }^{17)}$ Lactate was measured enzymatically. ${ }^{18)}$

Reagents:

ATP, CoA, L-carnitine and reagents for the determination of adenine 
nucleotides, creatine kinase and lactate were obtained from BoehringerMannheim-Yamanouchi, Tokyo. [1-14 G] palmitate was from New England Nuclear. POCA and TDGA were prepared by K. Niigata and N. Itoh at the Chemical Division of our laboratories. Other reagents were of analytical grade from commercial sources.

Statistics:

Analysis of differences was performed using the Student's t-test or the Newman-Keuls test.

\section{Results}

Inhibition of oxidation of palmitate in rat heart after POCA or TDGA pretreatment in vivo:

When fasted rats were injected s.c. with POCA $(15 \mathrm{mg} / \mathrm{kg})$ or TDGA $(5 \mathrm{mg} / \mathrm{kg}$ ) $120 \mathrm{~min}$ before in vitro experiments, the ability of their heart homogenate to oxidize $\left[1-{ }^{14} \mathrm{G}\right]$ palmitate to ${ }^{14} \mathrm{CO}_{2}$ was markedly diminished (Table I). Thus, inhibitory effects of both agents on FFA oxidation in vivo were well preserved under the in vitro conditions.

Effects of POCA and TDGA on changes in creatine kinase, lactate and coronary flow during 20 min reperfusion after 30 min ischemia:

Table II shows the effects of POCA and TDGA on creatine kinase and lactate leakage from perfused rat hearts during the $20 \mathrm{~min}$ period of reperfusion after $30 \mathrm{~min}$ ischemia. Rat hearts pretreated with either POCA or TDGA released less creatine kinase and lactate (POCA: $47.3 \%$ and 45.9\%, TDGA : $70.2 \%$ and $67.2 \%$, respectively) than did hearts from vehicle treated control rats. On the other hand, POCA and TDGA increased coronary flow by about $50 \% \quad(\mathrm{p}<0.05)$. These results indicated that the reduction of creatine kinase and lactate release induced by these two agents was not due to poor washout of creatine kinase and lactate by coronary flow.

Table I. Inhibition of Oxidation of Palmitate in Heart Homogenate after Pretreatment with POCA or TDGA in Vivo

\begin{tabular}{l|c|c}
\hline \multirow{2}{*}{} & \multicolumn{2}{|c}{ Oxidation of $\left[1-{ }^{14} \mathrm{C}\right]$ palmitate } \\
\cline { 2 - 3 } & $\mathrm{dpm} / \mathrm{mg}$ protein & Inhibition (\%) \\
\hline Control (5) & $12,231 \pm 373$ & 0 \\
POCA (6) & $5,004 \pm 278^{*}$ & $59.1 \pm 2.3^{*}$ \\
TDGA (6) & $5,327 \pm 300^{*}$ & $56.4 \pm 2.5^{*}$
\end{tabular}

$\mathrm{CO}_{2}$ formation from $\left[1-{ }^{14} \mathrm{C}\right]$ palmitate was measured as described in the Methods. Results are means $\pm S E$. Numbers of observations are shown in parentheses.

* $\mathrm{p}<0.05$, compared with control. 
Effects of POCA on the recovery of the pressure-rate product during reperfusion after 20 or 30 min ischemia:

As shown in Fig. 1A, maximum recoveries of product of [peak left ventricular pressure (LVP)-left ventricular end-diastolic pressure (LVEDP)] $\times$ heart rate (HR) on reperfusion after $20 \mathrm{~min}$ ischemia were attenuated by

Table 11. Effects of POCA and TDGA on Changes in Greatine Kinase, Lactate and Coronary Flow during 20 Min Reperfusion after 30 Min Ischemia

\begin{tabular}{l|c|c|c}
\hline & $\begin{array}{c}\text { Creatine kinase } \\
(\mathrm{U} / \mathrm{min})\end{array}$ & $\begin{array}{c}\text { Lactate } \\
(\mu \mathrm{mol} / \mathrm{min})\end{array}$ & $\begin{array}{c}\text { Coronary flow } \\
(\mathrm{ml} / \mathrm{min})\end{array}$ \\
\hline Control (7) & $1.71 \pm 0.09$ & $3.94 \pm 0.28$ & $9.13 \pm 0.58$ \\
POCA (6) & $0.90 \pm 0.20^{*}$ & $2.13 \pm 0.33^{*}$ & $14.12 \pm 1.28^{*}$ \\
TDGA (6) & $0.51 \pm 0.10^{*}$ & $1.29 \pm 0.10^{*}$ & $13.48 \pm 0.95^{*}$
\end{tabular}

POCA or TDGA was injected subcutaneously $120 \mathrm{~min}$ before the start of the perfusion. Samples of the coronary effluent were collected every $2 \mathrm{~min}$ except the first $5 \mathrm{~min}$ after the start of the reperfusion, during which the whole effluent was collected. The coronary flow was monitored by timed collection of perfusate. Results are means \pm SE. Numbers of observations are shown in parentheses.

* $\mathrm{p}<0.05$, compared with control.

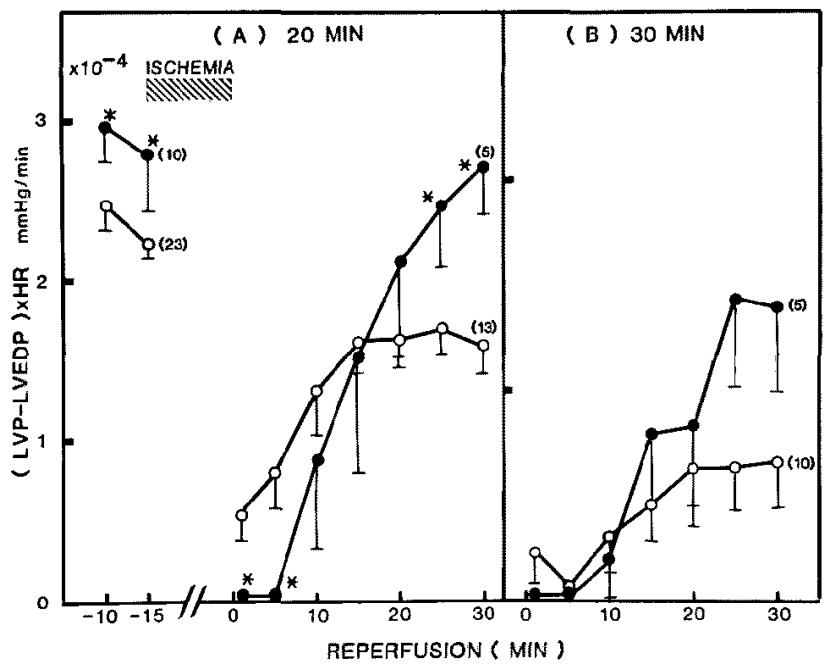

Fig. 1. Effect of POCA on the recovery of the pressure-rate product during reperfusion after $20 \mathrm{~min}(\mathrm{~A})$ or $30 \mathrm{~min}$ (B) ischemia.

POCA $(15 \mathrm{mg} / \mathrm{kg}$, ) or vehicle $(O)$ was injected s.c. $120 \mathrm{~min}$ before the start of the perfusion. Hearts were perfused for a $15 \mathrm{~min}$ control period, followed by differing periods of ischemia. Subsequently, hearts were reperfused for 30 min under non-ischemic conditions. Each point represents mean $+\mathrm{SE}$. Numbers of observations are shown in parentheses.

* $\mathrm{p}<0.05$, compared with control at the same interval. 
about $29 \%$ compared with the value before ischemia (at $-15 \mathrm{~min}, \mathrm{p}<0.05$ ). Furthermore, hearts exposed to $30 \mathrm{~min}$ of ischemia showed only $38.4 \%$ recovery of the pressure-rate product compared with the value before ischemia (Fig. 1B). On the other hand, after $20 \mathrm{~min}$ of ischemia, the pressure-rate product of POCA-treated hearts recovered significantly to their pre-ischemic values at the end of $30 \mathrm{~min}$ reperfusion, even though POCA increased the pressure-rate product by $21 \%$ under aerobic conditions before ischemia (at $-15 \mathrm{~min}, \mathrm{p}<0.05)$. However, there was no recovery of the pressure-rate product during the first $5 \mathrm{~min}$ of reperfusion.

As shown in Fig. 1B, POCA produced a recovery of the pressure-rate product to pre-ischemia control levels. The results in Fig. 1 showed that POGA improved the maximum recovery of the pressure-rate product on reperfusion after $20 \mathrm{~min}$ of ischemia and also delayed the recovery during the first 5 min of reperfusion.

Effects of POCA on changes in ATP,ADP and AMP concentrations of hearts exposed to differing periods of ischemia:

To investigate the possible relationship between the delayed recoveries of the pressure-rate product and adenine nucleotide concentration in hearts treated with POCA, the effects of POGA on ATP, ADP and AMP concentrations were examined in hearts as a function of the duration of the ischemic period (Fig. 2).

Myocardial ischemia (10-60 min) caused a progressive decrease in the ATP concentration, with concomitant increases in ADP and AMP concentrations in the control heart. However, ischemia longer than 20 min resulted in a significant reduction of the total concentration of adenine nucleotides (Table III). On the other hand, after $10 \mathrm{~min}$ of ischemia, POCA decreased both the ATP concentration from the control value of $16.3 \pm 0.8$ to $3.7 \pm 0.4$ $\mu \mathrm{mol} / \mathrm{g}$ dry wt (Fig. 2, $\mathrm{p}<0.05$ ) and the total adenine nucleotide concentration from $24.8 \pm 0.6$ to $13.0 \pm 0.7 \mu \mathrm{mol} / \mathrm{g}$ dry wt (Table III, $\mathrm{p}<0.05$ ). No further reductions in ATP concentrations were observed in hearts of POCA treated rats. TDGA also reduced ATP concentrations under the same ischemic conditions ( $10 \mathrm{~min}: 7.5 \pm 0.8,20 \mathrm{~min}: 2.5 \pm 0.1 \mu \mathrm{mol} / \mathrm{g}$ dry wt). These results suggested that the lower concentrations of ATP observed in ischemic hearts treated with POCA corresponded with a delayed recovery of the pressure-rate product.

Effects of reperfusion on the recovery of $A T P, A D P$ and $A M P$ concentrations of $P O C A$-treated hearts exposed to 30 min ischemia:

To further investigate the relationship between energy states and improved maximum recoveries of pressure-rate product in hearts treated with POCA, we measured myocardial ATP, ADP and AMP concentrations on 


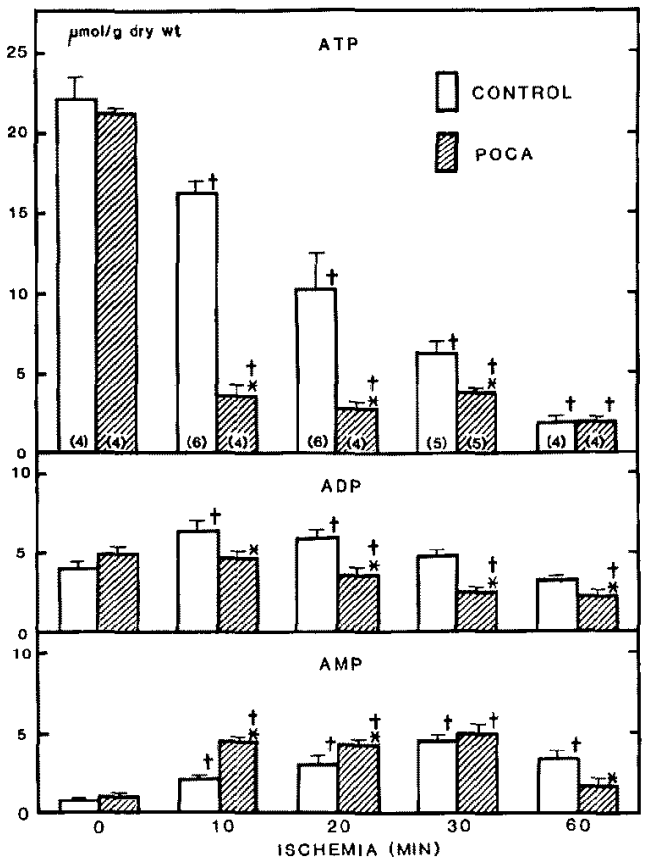

Fig. 2. Effects of POCA on changes in ATP, ADP and AMP concentrations of hearts exposed to differing periods of ischemia.

POCA was injected s.c. $120 \mathrm{~min}$ before the start of the perfusion. The hearts were perfused for a $15 \mathrm{~min}$ control period, followed by different periods of ischemia. For the determination of adenine nucleotide, hearts were quickfrozen at appropriate times of ischemia with aluminum clamps pre-cooled in liquid nitrogen. Each column represents mean $\pm \mathrm{SE}$. Numbers of observations are shown in parentheses.

* $\mathrm{p}<0.05$, compared with control at the same interval.

$+\mathrm{p}<0,05$, compared with the value before ischemia.

Table III. Effect of POCA on Changes in Total (ATP + ADP + AMP)

Concentrations Induced by Ischemia

\begin{tabular}{l|c|c|c|c|c}
\hline & \multicolumn{5}{|c}{ Period of ischemia $(\mu \mathrm{mol} / \mathrm{g}$ dry wt) } \\
\cline { 2 - 6 } & $0 \mathrm{~min}$ & $10 \mathrm{~min}$ & $20 \mathrm{~min}$ & $30 \mathrm{~min}$ & $60 \mathrm{~min}$ \\
\hline Control & $27.3 \pm 1.0$ & $24.8 \pm 0.6$ & $19.7 \pm 1.6 \dagger$ & $15.8 \pm 0.7 \dagger$ & $8.9 \pm 0.5 \dagger$ \\
POCA & $27.5 \pm 0.4$ & $13.0 \pm 0.7^{* \dagger}$ & $10.6 \pm 0.5^{* \dagger}$ & $11.6 \pm 0.5^{* \dagger}$ & $6.2 \pm 0.6^{* \dagger}$
\end{tabular}

The experimental procedure and numbers of observations are explained in Fig. 2. Results are means $\pm S E$.

* $p<0.05$, compared with control at the same interval.

$+\mathrm{p}<0.05$, compared with the value before reperfusion. 
reperfusion after $30 \mathrm{~min}$ ischemia. Before the start of reperfusion (zero time), the ATP concentration and the total concentration of adenine nucleotides observed in POCA-treated hearts were lower than in control hearts (Fig. 3 and Table IV). In contrast to the energy states during ischemia, POCA pretreatment resulted in ATP synthesis at higher rates than control during the first $10 \mathrm{~min}$ of reperfusion, the total concentration of adenine nucleotides also recovered above the control value. Thus, POCA-treated hearts showed much higher ATP concentrations than control hearts at 10 min (Fig. 3). This effect of POCA on ATP synthesis was also observed at 20 min of reperfusion. However, after $40 \mathrm{~min}$ of reperfusion, there was no significant difference between control and POCA treated rats (see Fig. 3 and Table IV). Thus, it is very likely that POCA reduced the tissue damage due to reperfusion after ischemia through the improvement of adenine nucleotide metabolism.

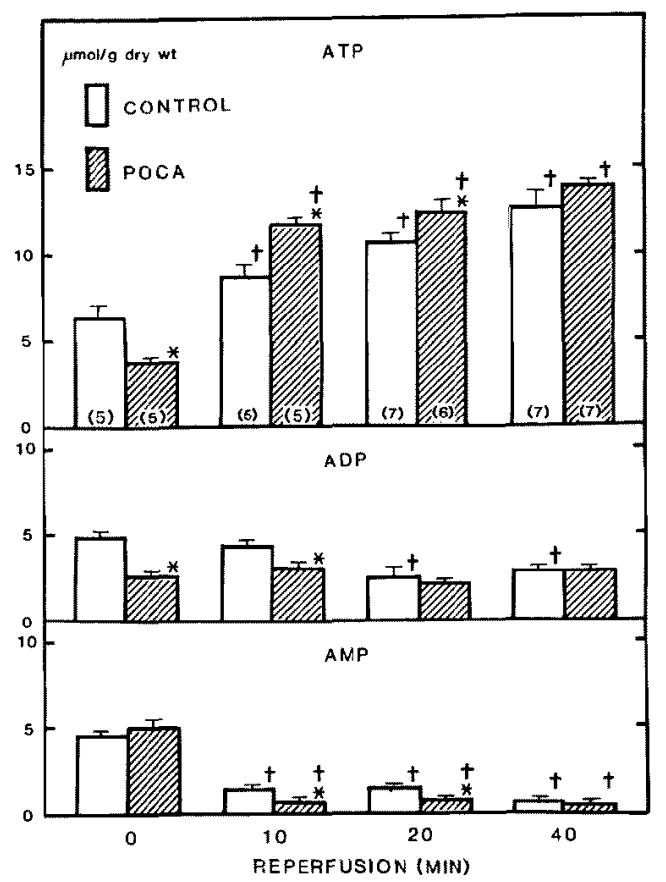

Fig. 3. Effects of reperfusion on the recovery of ATP, ADP and AMP concentrations of POCA-treated hearts exposed to $30 \mathrm{~min}$ ischemia.

POCA was injected $120 \mathrm{~min}$ before the start of the perfusion. After 30 min ischemia, hearts were reperfused in non-ischemic conditions. For the determination of adenine nucleotide, hearts were quick-frozen at appropriate times of reperfusion. Each column represents mean $\pm \mathrm{SE}$. Numbers of observations are shown in parentheses.

$* \mathrm{p}<0.05$, compared with control at the same interval.

$+\mathrm{p}<0.05$, compared with the value before reperfusion. 
Table IV. Effects of Reperfusion and POCA on Changes in Total (ATP + ADP + AMP) Concentrations Induced by $30 \mathrm{Min}$ Ischemia

\begin{tabular}{l|c|c|c|c}
\hline & \multicolumn{4}{|c}{ Period of reperfusion $(\mu \mathrm{mol} / \mathrm{g}$ dry wt) } \\
\cline { 2 - 5 } & $0 \mathrm{~min}$ & $10 \mathrm{~min}$ & $20 \mathrm{~min}$ & $40 \mathrm{~min}$ \\
\hline Control & $15.8 \pm 0.7$ & $14.7 \pm 0.8$ & $14.7 \pm 0.6$ & $16.5 \pm 1.0$ \\
POCA & $11.6 \pm 0.5^{*}$ & $15.6 \pm 0.1 \dagger$ & $15.7 \pm 0.5 \dagger$ & $17.5 \pm 0.3 \dagger$
\end{tabular}

The experimental procedure and numbers of observations are explained in Fig. 3. Results are means $\pm \mathrm{SE}$.

* $\mathbf{p}<0.05$, compared with control at the same interval.

$+\mathrm{p}<0.05$, compared with the value before ischemia or reperfusion.

\section{DisGussion}

Using a Langendorff rat heart preparation, we examined the effects of POCA and TDGA, irreversible acylcarnitine-transferase inhibitors, on damage induced by ischemia of variable duration. The results indicated that POCA-treated hearts showed about a $60 \%$ inhibition of FFA oxidation and recovered stable mechanical functions (pressure-rate product) after $20 \mathrm{~min}$ ischemia. Hearts perfused without this agent failed to recover to preischemic values (Table I and Fig. 1). From the studies of Pearce et al ${ }^{111}$ with working rat heart preparations, the addition of $1 \mathrm{mM}$ oleate to the perfusate resulted in a reversible decrease in left ventricular pressure development and aortic output under hypoxic conditions. They also showed that perfusion with TDGA $(50 \mu \mathrm{M})$ prevented this deleterious effect of oleate. Therefore, it is highly possible that FFA oxidation is one of the causes for the deleterious effects of ischemia as well as hypoxia on mcchanical failure.

Current studies have suggested that the deleterious effects of ischemia are characterized by early falls in cellular concentrations of high energy phosphates (ATP and creatine phosphate).193,201 At much later stages, this damage is evidenced by a major leakage of intracellular enzymes (e.g., creatine kinase, lactate dehydrogenase) and by a myocardial contracture.19,21) If myocardium is reperfused after significant cellular damage has occurred, reperfusion itself accelerates tissue damage.

In accord with these current studies, POCA and TDGA reduced the ischemic injury, evidenced by a less intensive release of creatine kinase $(47.3 \%$ and $70.2 \%$ reduction, respectively) (Table II). They also suppressed the release of lactate, indicating improvement of the unbalanced redox state induced by ischemia. Furthermore, the most striking effects of POCA during the reperfusion period was that this agent increased ATP synthesis at higher rates than control. As a result of this effect, POCA-treated hearts showed 
significantly higher ATP concentrations than those in control hearts. Thus, it is very likely that POCA preserved cardiac cellular function.

A different picture emerged when the effects of POCA on ATP, ADP and AMP concentrations during ischemia were examined (Fig. 2). This treatment caused drastic reductions in both ATP and the total concentration of adenine nucleotides after $10 \mathrm{~min}$ of ischemia. POCA-pretreatment decreased ATP concentrations at three times the rate of the control group during the first $10 \mathrm{~min}$ of ischemia (Fig. 2). It is well established that depleted high energy phosphate stores (ATP and creatine phosphate) are associated with loss of contractile integrity and a rigor-like state, evidenced by a rise in enddiastolic pressure. ${ }^{22)}$ Seitelberger et ald $^{12}$ showed that POCA impaired regional myocardial contractility in underperfused canine myocardium. Therefore, it is highly possible that the delayed recovery of the pressure-rate product observed in POCA-treated hearts corresponded closely with contractile failure due to depleted ATP concentration.

Little is known about the underlying causes for myocardial ATP reduction induccd by acylcarnitinc-transferase inhibitors during ischemia. However, one possibility is that FFA are the principal myocardial energy substrate during the ischemic period and well-oxygenated conditions. ${ }^{23)}$ The inhibition of endogenous FFA oxidation by POCA resulted in a shortage of substrate for ATP synthesis, even though the utilization of glucose and endogenous glycogen was enhanced. Pearce et al $^{113}$ indicated that at high work load (400 beats/min), TDGA addition $(10 \mu \mathrm{M})$ resulted in decreased cardiac function. This change may reflect an inhibition of endogenous FFA oxidation, since $5 \mathrm{mM}$ glucose was added into the perfusion medium as the only exogenous substrate. Thus, endogenous FFA are still an important substrate when energy demand is exceeded.

Another possibility is that the accumulation of FFA and acyl-CoA derivatives induced by acylcarnitine-transferase inhibitors during ischemia may inhibit ATP synthesis by the inhibition of adenine nucleotide translocase ${ }^{4)}$ or uncoupling effects of oxidative phosphorylation. ${ }^{24)}$. Bachmann et $\mathrm{al}^{25)}$ reported that mitochondria, isolated from the hearts dosed with TDGA for 4 weeks, showed progressive uncoupling of oxidative phosphorylation (decrease in ADP/O ratio), with concomitant changes in electron transfer reaction (oxygen consumption). However, it is apparent in this study that POCA did not display an uncoupling effect of oxidative phosphorylation at normoxic conditions, since this agent did not affect the ATP concentration before ischemia (Fig. 2). 


\section{References}

1. Karwatowska-Krynska E, Beresewicz A: Effect of locally released catecholamines on lypolysis and injury of the hypoxic isolated rabbit heart. J Mol Cell Cardiol 15: 523, 1983

2. Manning A, Keogh J, Hearse DJ, Coltart J: Beta-blockade and ischemic injury: effects of partial agonist activity. Cardiovasc Res 14: 619, 1980

3. Mjøs OD: Effect of free fatty acid on myocardial function and oxygen consumption in intact dogs. J Clin Invest 50: 1386, 1971

4. Shrago $\mathrm{E}$ : The effect of long chain fatty acyl CoA esters on adenine nucleotide translocase and myocardial metabolism. Life Sci 22: 1, 1978

5. Higgins AJ, Morville M, Burges RA, Blackburn KJ: Mechanism of action of oxfenicine on muscle metabolism. Biochem Biophys Res Commun 100: 291, 1981

6. Tutwiler GF, Ryzlak MT: Inhibition of mitochondrial carnitine palmitoyl transferase by 2-tetradecylglycidic acid (McN-3802). Life Sci 26: 393, 1980

7. Turnbull DM, Bartlett K, Younan SI, Sherratt HSA: The effects of 2[5-(4-chlorophenyl)pentyl] oxirane-2-carbonyl-CoA on mitochondrial oxidations. Biochem Pharmacol 33: 475, 1984

8. Tutwiler GF, Ho W, Mohrbacher RJ: 2-Tetradecylglycidic acid. Methods in Enzymology 72: 533,1981

9. Higgins AJ, Morville M, Burges RA, Gardiner DG, Page MG, Blackburn KJ: Oxfenicine diverts rat muscle metabolism from fatty acid to carbohydrate oxidation and protects the ischaemic rat heart. Life Sci 27: 963, 1980

10. Burges RA, Gardiner DG, Higgins AJ: Protection of the ischaemic dog heart by oxfenicine. Life Sci 29: 1847, 1981

11. Pearce FJ, Forster J, Deleeuw G, Williamson JR, Tutwiler GF: Inhibition of fatty acid oxidation in normal and hypoxic perfused rat hearts by 2-tetradecylglycidic acid. J Mol Gell Cardiol $11: 893,1979$

12. Seitelberger R, Kraupp O, Winkler M, Brugger G, Raberger G: Effects of the acylcarnitinetransferase blocking agent sodium 2[5-(4-chlorophenyl)-pentyl]-oxirane-2-carboxylate (POCA) on metabolism and regional function in the underperfused canine myocardium. J Cardiovasc Pharmacol 7: 273, 1985

13. Lowry $\mathrm{OH}$, Rosebrough NJ, Farr AL, Randall RJ: Protein measurement with the folin phenol reagent. J Biol Chem 193: 265, 1951

14. Neely JR, Revetto MJ: Techniques for perfusing isolated rat heart. in Methods in Enzymology, ed by Hardman JG, O'Mally BW, Vol 139, Academic Press, New York, p 43, 1974

15. Jaworek D, Gruber W, Bergmeyer HU: Adenosine-5'-triphosphate, determination with 3phosphoglycerate kinase. in Methods of Enzymatic Analysis, ed by Bergmeyer HU, Academic Press, New York, p 2097, 1974

16. Jaworek D, Gruber W, Bergmeyer HU: Adenosine-5'-diphosphate and adenosine-5' ${ }^{\prime}$-monophosphate. in Methods of Enzymatic Analysis, ed by Bergmeyer HU, Academic Press, New York, p 2127, 1974

17. Urdal $\mathrm{P}$, Stromme $\mathrm{JH}$ : Effects of $\mathrm{Ca}^{++}, \mathrm{Mg}^{++}$and EDTA on creatine kinase activity in cerebrospinal fluid. Clin Chem 25: 147, 1979

18. Gutmann I, Wahlefeld AW: L- $(+)$-lactate, determination with lactate dehydrogenase and NAD. in Methods of Enzymatic Analysis, ed by Bergmeyer HU, Academic Press, New York, p 1464,1974

19. Shikama $\mathrm{H}$, Noshiro $\mathrm{O}$, Ohta A, Ohata $\mathbf{I}$ : Effects of nicardipine on ischemic mechanical failure and tissue injury in isolated perfused rat heart. Jpn Heart J 26: 813, 1985

20. Hearse DJ, Crome R, Yellow DM, Wyse R: Metabolic and flow correlates of myocardial ischaemia. Cardiovasc Res 17: 452, 1983

21. Kloner RA, Braunwald E: Observations on experimental myocardial ischemia. Cardiovasc 
Res 14: 371,1980

22. Takeo S, Sakanashi M: Possible mechanisms for reoxygenation-induced recovery of myocardial high-energy phosphate after hypoxia. J Mol Cell Cardiol 15: 577, 1983

23. Oram JF, Suzamme L, Bennetch L, Neely JR: Regulation of fatty acid utilization in isolated perfused rat hearts. J Biol Chem 248: 5299, 1973

24. Katz AM, Messineo FC: Lipid-membrane interactions and the pathogenesis of ischemic damage in the myocardium. Circ Res 48: 1, 1981

25. Bachmann E, Weber E, Zbinden G: Biochemical aspects of cardiotoxic effects of a novel type hypoglycemic agent in rats. J Mol Cell Cardiol 15 (suppl 1): 67, 1983 